\title{
Work in Progress: Professional Development Module in First-Year Engineering Course
}

\section{Dr. Olukemi Akintewe, University of South Florida}

Dr. Olukemi Akintewe is an instructional faculty in the Medical Engineering Department at the University of South Florida. She received a B.E. degree in chemical engineering from City College of New York, CUNY, a M.Sc in materials science and engineering from the Ohio State University and a Ph.D. in chemical engineering from the University of South Florida. Dr. Akintewe's research focuses on projectbased learning in engineering education; engineering predictive assessment models that supports students' learning, classroom management techniques and best teaching practices.

\section{Dr. Jonathan Elliot Gaines, University of South Florida}

Jonathan E. Gaines is faculty in the Mechanical Engineering Department at the University of South Florida. He is the Director of First Year Experiential Education and Learning. Through this position, he develops and implements the curriculum for USF's Foundations of Engineering Lab course. He is also the Principle Investigator for Bulls Engineering Youth Experience (Bulls-EYE Mentoring) a Science, Technology, Engineering, and Math based outreach program that uses undergraduate students to mentor middle school youth.

\section{Anna Maria Bateman, The University of South Florida}

I am a second-year graduate student at the University of South Florida (USF) pursuing my Masters of Education in Curriculum and Instruction within the College Student Affairs program. As the Graduate Assistant for the Office of Internships and Career Readiness at USF, I hired, trained, and supervised the Career Readiness Badging Peers who are our Federal Work Study students within the office. I trained the students to grade, through the use of success rubrics and the ARISE model which was adapted from the RISE model created by Emily Wray from Full Sail University in conjunction with the COACH feedback method, student submissions within the Career Readiness Badging Program (CRBP). The CRBP is a platform on Canvas that allows students at USF to earn badges in association with the eight competencies the National Association of Colleges and Employers use to help define "career readiness" for college students.

\section{Ms. Lynn Chisholm, The University of South Florida}

Lynn Chisholm is the Director of the Office of Internships and Career Readiness at the University of South Florida, as well as Adjunct Faculty for the Florida State University Certified Public Manager program for workforce and leadership development. At USF, Lynn co-developed (with Peter Thorsett, MPA at USF) and administers the system-wide (NACE recognized, SoACE awarded) Career Readiness Badging Program, and supervises her team in providing High-Impact Practices experiential learning programming to USF's 50,000+ students. Lynn has been academic faculty at FSU, UGA, and Polk State, and is now in administration at USF. She earned her bachelor's degree at UCF, and her master's degree at Boston University. 


\title{
Work in Progress: Professional Development Module in First- Year Engineering Course
}

\begin{abstract}
This Work in Progress paper describes the Professional Development (PD) module adopted for a first-year interdisciplinary engineering course at a research university in the southeastern region of the United States. The goal of the PD module is to prepare students for successful careers in engineering by developing essential soft skills. This paper reports the approach taken to improve an engineering course by incorporating a PD component. This is a 3-credit first-year engineering foundations laboratory course, which focuses on the fundamentals of design processes. In its first iteration, over 500 first-year students performed three sequential assignments to complete the module. These students methodically engaged in a career readiness process within a program that documents achievement while promoting their academic growth. The intent is to present professional contexts as part of their undergraduate experience.

The PD module in this course is initiated by students' automatic enrollment in the institution's Career Readiness Badging Program (CRBP) - a program developed to address the ascribed National Association of Colleges and Employers (NACE) eight core competencies employers seek in recent graduates entering the workforce. These skills include Technology, Critical thinking, Global Citizenship, Teamwork, Career Management, Leadership, Professionalism and Communications. A digital badge is earned upon student's demonstration of any of the eight NACE skill sets. Demonstration of these skills is documented using the CRBP three-section assignment format: Learn it; Do it and Show it. The Learn it section documents how a particular NACE skill was learned. The Do it portion consists of students completing an experience outside of the classroom (i.e. volunteer service, internship, job or student organizations) that requires the use of the learned skill. While the Show it assignment involves students submitting a video describing a time when the skill was used. Completion of the CRBP does not only provide students with digital badges that can be displayed on career management platforms and resumes, but it teaches students how to communicate all learned skills to employers.

The University of South Florida first-year engineering coursework learning outcomes provide students with opportunities to learn six of the eight NACE competencies (all except global citizenship and career management). Students are required to work on only one badge to fulfill the course PD requirement. With $76 \%$ of freshmen engineering students successfully completing the CRBP, it is anticipated that these students will continue to earn one badge per semester achieving all eight NACE competency skills before graduation. Ultimately, the opportunities for students to develop soft skills in conjunction with a curriculum that instructs engineering core competencies is important for success in the professional realm.
\end{abstract}

\section{Introduction}

Universities are revamping their first-year engineering curriculum to feature high impact activities promoting professional development (PD) [1-5]. Oftentimes, this comes in the form of long-term design project assignments or real world case studies [1-4, 6]. Even when logistical challenges are vast $[7,8]$, as in large lecture course $(>60)$, it has been of increased 
importance to provide every first-year student with these experiences [2, 9-11]. There are, however, three primary challenges that make implementing PD experiences especially difficult in large lecture courses. First, these are students at the beginning of their collegiate matriculation and therefore may have little to no experience in professional environments. Their base skills are usually underdeveloped and exposure to ill-formed problems are wholly lacking. Second, students enter the engineering design environment with disparate skills based on a variety of previous academic experiences. Finding the base reference point common to most students makes curriculum building a challenge. And third, the sheer number of students involved in first-year courses makes timely effective assessment and feedback a logistical challenge. As a result, building a knowledge base for how to successfully implement PD into large first-year engineering programs is appealing.

Several universities are now structuring programs to include PD components earlier because the impact on pluralistic outcomes is clear [12]. First-year engineering and computing students are being exposed to environments that contextualize the curriculum. Many large universities have taken steps to afford their students opportunities to work with real stakeholders and industry partners - taking part in engineering design processes, rapid prototyping, problem solving, organizational leadership, and systems communication. But, for large lecture courses, there is a unique difficulty in creating cognitive objectives inherent to the three primary challenges to implementing PD. A critical aspect is providing a structure that is comprehensive yet flexible enough to accommodate different backgrounds. Upon completion, students must be able to reflect upon their experiences and communicate its value to potential employers and other professionals in the engineering field. In turn, institutions need an effective way to assess learning outcomes.

Over the past 10 years, digital badging has gained momentum in formal and informal settings as a way to document skills achieved [13-17]. Digital badging is best understood as a merit-based award given to students when particular criteria are met to demonstrate a competency. Although belief in the usefulness of digital badges to promote traditional learning has been mixed [15-16, 18-20], usage to indicate professional competencies has seen wider acceptance [16, 21-23]. Additionally, the types of soft skills employers' value like teamwork and leadership are difficult to quantify traditionally, so digital badges express students' academic experiences more completely. As such, badging supports developing key skills while celebrating individual achievement. This is particularly true when self-directed learning is central to the approach [18].

For its strengths in documenting skills and experiences, digital badging has been adopted for first-year engineering design and computing instruction [21-24]. Although initial results are promising, a longer-term assessment is needed to determine if PD components are effective in large lecture courses. Additionally, alternative methods of assessment are needed for evaluating PD coursework in a manner that provides added dimension. In this paper, badging is explored as a viable means to assess and document PD competencies in first-year engineering design; and the three-assignment sequence as a means for achieving one of eight NACE competencies.

The engineering course at the University of South Florida (USF) was designed specifically to address challenge one as outlined above. Students use a project-based and service-learning 
approach [25] to obtain realistic engineering design experiences and skills. But, the unique contribution of this paper is the presentation of how the course assesses and documents PD experiences in a large class size. A three-assignment sequence was adapted in order to provide an opportunity to leverage experiences in the class and build towards competency achievement. Efficiency and efficacy is served by affording each student an opportunity to earn badges simply by completing course requirements.

\section{Research Approach}

Study on the feasibility of implementing a PD module based on the eight NACE competencies is investigated in a large course enrollment. USF CRBP provides a platform for documenting and providing feedback for each competency. CRBP instructors assess students' ability to communicate ascribed learning objectives with respect to fabrication, design and analysis of the competency.

\section{First-Year Engineering Foundations Lab Course Structure}

First-year and transfer students at the University of South Florida are required to enroll in a 3credit Foundations of Engineering Lab course. Student enrollment was approximately 518 per semester representing different undergraduate engineering and computing programs offered at USF. This course requires students to apply design processes outlined by Ulrich and Eppinger [26] while working in groups of 4-5 to produce a functional prototype [25]. The PD module is sectioned into three assignments, which is consistent with assessment levels ascribed by the CRBP.

\section{Course Learning Outcomes Exemplifies NACE Competencies}

NACE established eight "career readiness" competencies after surveying employers to determine a clearer definition of what encompasses career readiness [28]. These competencies are Professionalism, Critical Thinking, Leadership, Communication, Teamwork, Technology, Global Citizenship and Career Management. Professionalism is the competency that encompasses appropriate behavior, timeliness, and professional attire in the workplace. Critical Thinking is comprised of creating decisive solutions within the confines of competing ideas. Leadership prompts one to show selflessness, placing team and its success as priority. Those who have this skill are believed to maintain high ethical standards and are good at delegating tasks. Communication entails written and oral; proper etiquette in correspondence is important. Teamwork involves being effective and efficient while working with others - in spite of diverging beliefs. Obtaining the Technology competency implies adaptiveness for various projects. Global Citizenship shows cultural awareness, emphasizing respect for diversity. Lastly, Career Management is about long-term professional relevance. Cognizance of emerging career options is key to maintaining relevancy in the job market.

This first-year engineering course provides a platform to acquire six of the eight competencies (Critical thinking, Communication, Teamwork, Technology, Leadership and Professionalism). However, students were not limited to only those choices for the CRBP. The following describes how the other competencies can be earned in this course: 
- Teamwork: Students work in groups of 4-5 with defined lead roles such as Engineering technology, Manufacturing, Education Materials, and Communications leads.

- Technology: Students are required to use CAD software and 3D printers for their respective design projects.

- Leadership: Students are expected to exercise leadership according to their assigned roles such as Engineering technology lead, 3D printing/Manufacturing lead, Internal/external communication lead and Education Materials lead.

- Communication: Course deliverables include oral and written reports.

- Critical thinking: Course module includes design reviews and fabrication deliverables.

- Professionalism: Student code of conduct is enforced throughout the course.

\section{How University of South Florida implements the NACE Competencies via CRB Program}

Lynn Chisholm and Peter Thorsett of the Division of Community Engagement and Career Readiness developed CRBP at the University of South Florida in 2017 through an evaluative process input from faculty, staff and students. The program is administered online via Canvas learning management system and designed to provide students the opportunity to earn digital badges for each NACE competency. To obtain a badge, students must complete three assessments. The assessments are categorized into: Learn It, Do It, and Show It.

Learn It is comprised of two deliverables. The Learn It Submission Form where students identify the activity and time period in which the competency was acquired, and the Learn It Self-Assessment which consists of five multiple-choice questions that is automatically graded in Canvas. The assessment, which aligns with Bloom's taxonomy, identifies the degree to which students reached the competency objectives.

Do It also has two deliverables. The Do It Submission Form requires students to complete an experience activity of their choice that focuses on the essential skill. Students document the capacity in which the competency was displayed. For example, community engagements, organizational leadership roles, volunteer services, service-learning programs and other approved settings. The second deliverable is the Do It Self-Assessment, which consists of three questionnaires. Students answer questions about their competency and provide a portion of their resume that illustrates it.

The last section, Show It, is where students create a 1 to 2-minute video recording of themselves answering a behavioral-based interview question. Herein, CRBP evaluators follow a rubric to assess students' ability to adhere to the interview behavioral style using the STAR-L (Situation, Task, Action, Result, and Learned) method. Evaluators provide feedback using Emily Wray's RISE and the program's ARISE (Align, Reflect, Inquire, Suggest, and Elevate) [27] models embedded into the COACH (Clarify, Objective, Action, Check, and Help) framework.

In the Learn it and Do it sections, students must score a grade $\geq 90$ on a scale of 100 and complete the Show it section to earn the digital badges. Once all three sections have been successfully completed, students are prompted to create a "Badgr Backpack" - a virtual storage file for digital badges. The earned badge would display the competency that can then 
be shared on any professional career management outlet such as LinkedIn and Handshake.

\section{Results and Discussion}

\section{Course offering aided student's competency skills}

This first-year engineering laboratory course structure offered six of the eight NACE core competencies. Figure 1 show the percentages of students enrolled in each competency; Teamwork (25\%), Leadership (18\%), and Communication (17\%) accounting for 50\% of the selections. Reasons for these selections may be attributed to any of three postulations: 1) students recognize these competencies as the most important to obtain prior to seeking employment; 2) these competencies are most familiar to students; and 3) students are influenced by their assigned roles in the course projects. The individual project roles and responsibilities provide opportunities to work on leadership and communication. For example, the responsibility of the 3D printing and manufacturing lead ensures the project's computer-aided design (CAD) file is manufactured according to the course specifications, while the communications lead is responsible for managing and disseminating information on behalf of the group.

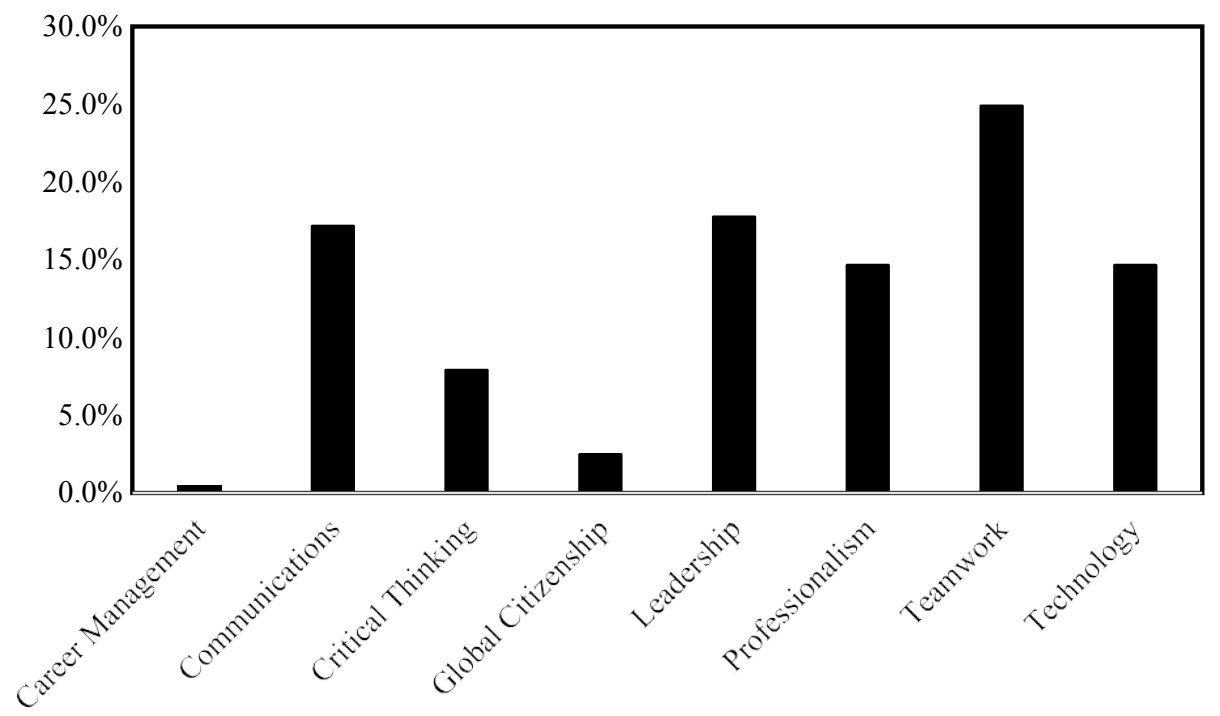

Figure 1: Distribution of students by competency enrollment.

Critical thinking, although an important competency, was the least chosen of the six badges offered through the course. Though Global Citizenship was not within the scope of this course, less than $5 \%$ of the students chose this competency. Students were discouraged from selecting Career Management since they would need to have an updated Handshake account (a talent recruitment system) among other requirements. Thus, only two students pursued the Career Management competency. Note that CRBP is only a connection and documentation platform; the program does not offer resources for learning about any of the competencies. Therefore, students may only choose to work on badges that they are acquainted with. 
Figure 2 displays the grades earned in the Learn-it, Do-it and Show-it sections. Distribution of grades for Show-it was a Complete, an Incomplete (score of 50 or lower) or a score of 0 for no submission. For Learn-It Self-Assessment, at least $99 \%$ of the students earned a passing grade of $\geq 90$ compared to the Do-It Self-Assessment where approximately only $56 \%$ students passed. Learn-It Self-Assessment is graded automatically in Canvas so students were able to move to the next section relatively faster than the Do It Self-Assessment, which is only graded manually. The assessment forms evaluated students' abilities to communicate their experience technically. Reports from the Do-it assessment revealed a wide range of contributed effort indicating that first-year engineering students need more training with written technical communication. Since part of the objective was to provide opportunities to earn digital badges, all students were allowed to proceed to the Show it section even before receiving their Do-it grades. However, students will have to earn a passing grade in respective sections to earn a badge.

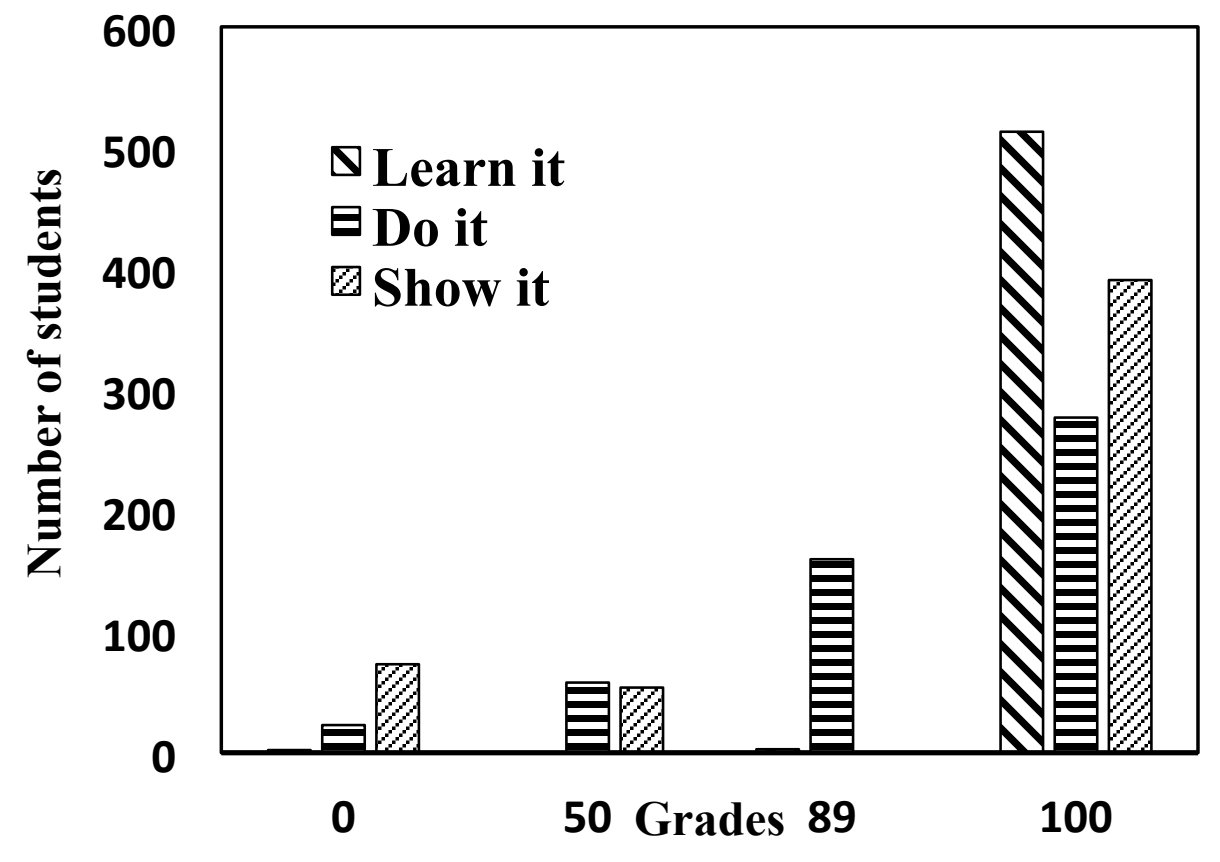

Figure 2: Grades earned by students in each CRBP section; Learn it, Do it and Show it. The lowest bars at 0 and 89 correspond to the Learn it section.

Figure 2 also shows that Do-it was the most challenging for engineering students to pass compared to the Learn-it section. This is also implied by the $76 \%$ of students (figure $3 a$ ) who completed the Show-it section. The $24 \%$ of student who had incompletes or made no submissions (figure 3a) may have had different factors that affected their ability to complete the assignment. While assignment deadlines are firm and communicated prior to each assignment, students face a range of challenges that affect their work. Also, depending upon how much the assignment contributes to the course overall grade, students may elect not to re-submit work for improved grades. A significant portion of the $14 \%$ of students with no submission (figure $3 \mathrm{a}$ ) represents those who ended their participation in the course. Figure $3 \mathrm{~b}$ reveals the total number of badges earned per competency; it is noted that the two students who chose the Career 
Management competency did not complete the requirements to earn the badge.

(a)

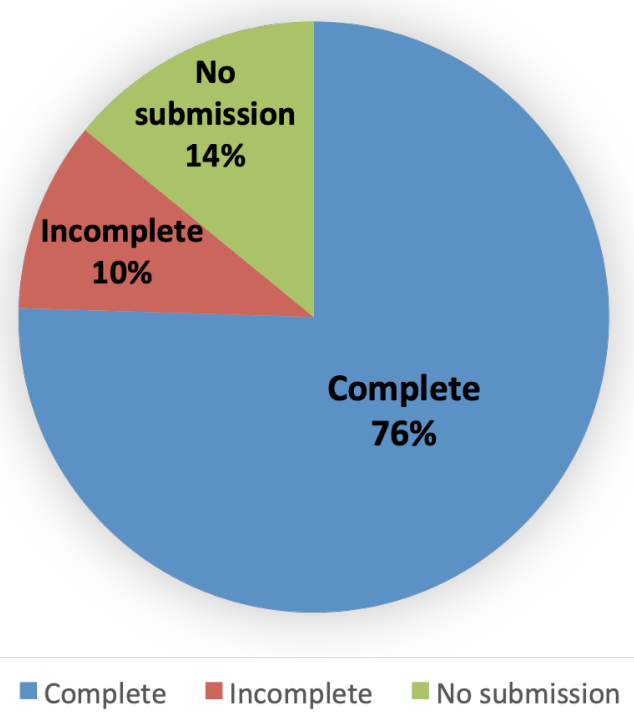

(b)

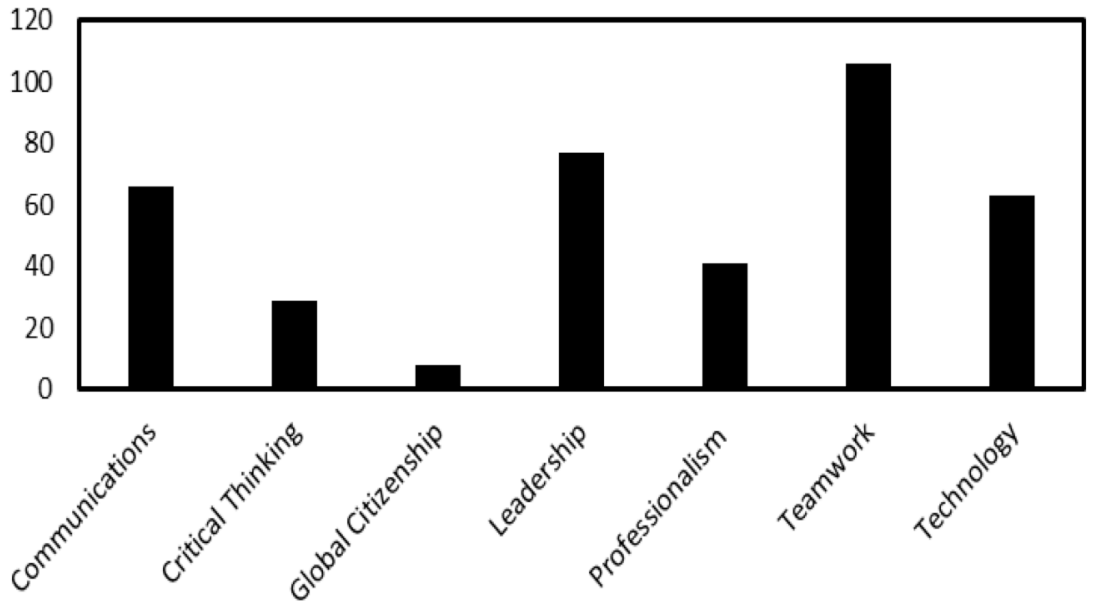

Figure 3: (a) Percentage of students who earned one of the NACE badges. (b) Distribution of badges earned by the $76 \%$ of students who completed the CRBP.

Managing the program for a large class size poses challenges mainly in providing feedback. Nevertheless, the significance of this study may only be measurable when this set of first-year students reaches their final year - when job searching begins. And giving that the CRBP is relatively new ( $\sim 3$ years old), there is insufficient data on the impact of career readiness badges on employer hiring. Nonetheless, PD is intrinsic to the engineering profession. 
A reflection survey conducted on professional development at the end of the semester revealed that engineering students found the PD module to be useful in documenting their soft skills. Though the recognition of a competency is an incentive; crucial, was learning to communicate their competencies on resumes and career management systems. Here are excerpts from student feedbacks: "I worked on the Leadership badge... I think the earning of badges as a piece of the course is very valuable because it encourages people who otherwise wouldn't have pursued the badging course to earn something to place on their resume, and it shows them how to continue earning badges in the future."

"I enjoyed being able to earn a badge that I can now put on my resume, turning my past experiences into a Career Asset."

"I learned about the characteristics and tasks that leaders must fulfill and I also learned how to present my leadership skills on my resume."

Students also mentioned that the PD module allowed them to reflect on their core competencies, desired skills and career aspirations, thus enhancing the overall first-year engineering academic experience.

\section{Conclusion and Future Direction}

We have demonstrated how to implement and assess professional development in a first-year engineering course with an enrollment of at least 500 students per semester. In order to hone individual soft skills prior to graduation, we anticipate that students will continue to earn additional digital badges that showcase one or more of the eight NACE core competencies as they progress through their engineering undergraduate curriculum. Nevertheless, the ability to provide students with opportunities to document and acquire essential professional competencies is important for student's professional development and beyond the first-year programs. 


\section{References}

[1] J. E. Brownell and L. E. Swaner, "High-impact practices: Applying the learning outcomes literature to the development of successful campus programs," Peer Rev., vol. 11 , no. 2, p. 26, 2009.

[2] C. A. Kilgo, J. K. E. Sheets, and E. T. Pascarella, "The link between high-impact practices and student learning: Some longitudinal evidence," High. Educ., vol. 69, no. 4, pp. 509- 525, 2015.

[3] G. D. Kuh, "Excerpt from high-impact educational practices: What they are, who has access to them, and why they matter," Assoc. Am. Coll. Univ., vol. 14, no. 3, pp. $28-$ 29, 2008.

[4] D. Pusca and D. O. Northwood, "Implementation of high-impact practices in engineering design courses," World Trans Engng Technol Educ, vol. 16, no. 2, pp. 108-114, 2018.

[5] A. K. Ribera, A. L. Miller, and A. D. Dumford, "Sense of peer belonging and institutional acceptance in the first-year: The role of high-impact practices," J. Coll. Stud. Dev., vol. 58, no. 4, pp. 545-563, 2017.

[6] C. Sandeen, "High-Impact Educational Practices: What We Can Learn from the Traditional Undergraduate Setting," Contin. High. Educ. Rev., vol. 76, pp. 81-89, 2012.

[7] K. Lund Dean and S. Wright, "Embedding engaged learning in high enrollment lecture- based classes," High. Educ., vol. 74, no. 4, pp. 651-668, Oct. 2017, doi: 10.1007/s10734- 016-0070-4.

[8] W. R. Watson, S. L. Watson, S. T. Magar, and L. Tay, "Comparing attitudinal learning of large enrolment active learning and lecture classes," Innov. Educ. Teach. Int., pp. 1-11, Jan. 2020, doi: 10.1080/14703297.2019.1711440.

[9] J.-P. Faletta, J. A. Meier, and J. U. Balderas, "High-Impact Practices: Integrating the First- Year Experience with Service-Learning and Study Abroad," Handbook of Research on Effective Communication in Culturally Diverse Classrooms, 2016. [Online]. Available: https://www.igi-global.com/chapter.aspx?ref=high-impactpractices\&titleid=146366. [Accessed: 02-Feb-2020].

[10] M. W. McBroom, S. H. Bullard, D. Kulhavy, and D. R. Unger, "Implementation of collaborative learning as a high-impact practice in a natural resources management section of freshman seminar," 2015.

[11] S. McMahan, "Creating A Model For High Impact Practices At A Large, Regional, Comprehensive University: A Case Study," Contemp. Issues Educ. Res. CIER, vol. 8, no. 2, pp. 111-116, Apr. 2015, doi: 10.19030/cier.v8i2.9144.

[12] K. M. Soria and M. Johnson, "High-Impact Educational Practices and the Development of College Students' Pluralistic Outcomes," Coll. Stud. Aff. J., vol. 35, no. 2, pp. 100116, Nov. 2017, doi: 10.1353/csj.2017.0016.

[13] K. L. Carey and J. E. Stefaniak, "An exploration of the utility of digital badging in higher education settings," Educ. Technol. Res. Dev., vol. 66, no. 5, pp. 1211-1229, Oct. 2018, doi: 10.1007/s11423-018-9602-1.

[14] C. Casilli and D. Hickey, "Transcending conventional credentialing and assessment paradigms with information-rich digital badges," Inf. Soc., vol. 32, no. 2, pp. 117-129, Mar. 2016, doi: 10.1080/01972243.2016.1130500. 
[15] P. Dyjur and G. Lindstrom, "Perceptions and Uses of Digital Badges for Professional Learning Development in Higher Education," TechTrends, vol. 61, no. 4, pp. 386-392, Jul. 2017, doi: 10.1007/s11528-017-0168-2.

[16] A. Elkordy, "Development and Implementation of Digital Badges for Learning Science, Technologly, Engineering and Math (STEM) Practices in Secondary Contexts: A Pedagogical Approach with Empirical Evidence," in Foundation of Digital Badges and Micro-Credentials: Demonstrating and Recognizing Knowledge and Competencies, D. Ifenthaler, N. Bellin-Mularski, and D.-K. Mah, Eds. Cham: Springer International Publishing, 2016, pp. 483-508.

[17] N. Ostashewski and D. Reid, "A History and Frameworks of Digital Badges in Education," in Gamification in Education and Business, T. Reiners and L. C. Wood, Eds. Cham: Springer International Publishing, 2015, pp. 187-200.

[18] S. Cucchiara, A. Giglio, D. Persico, and J. E. Raffaghelli, "Supporting Selfregulated Learning Through Digital Badges: A Case Study," in New Horizons in Web Based Learning, Cham, 2014, pp. 133-142, doi: 10.1007/978-3-319-132969 - 15.

[19] C. Gamrat, H. T. Zimmerman, J. Dudek, and K. Peck, "Personalized workplace learning: An exploratory study on digital badging within a teacher professional development program," Br. J. Educ. Technol., vol. 45, no. 6, pp. 1136-1148, 2014, doi: $10.1111 /$ bjet.12200.

[20] R. Rughiniş and S. Matei, "Digital Badges: Signposts and Claims of Achievement," in HCI International 2013 - Posters' Extended Abstracts, Berlin, Heidelberg, 2013, pp. 8488, doi: 10.1007/978-3-642-39476-8_18.

[21] H. Shahriar, S. Peletsverger, H. Zafar, B. Bailey, and L. Johnston, "Digital Badges to Enhance Skills and Preparation for a Career in Cyber Security," in 2016 IEEE 40th Annual Computer Software and Applications Conference (COMPSAC), 2016, vol. 2, pp. 622-623, doi: 10.1109/COMPSAC.2016.97.

[22] S. Hensiek, B. K. DeKorver, C. J. Harwood, J. Fish, K. O’Shea, and M. Towns, "Improving and Assessing Student Hands-On Laboratory Skills through Digital Badging," J. Chem. Educ., vol. 93, no. 11, pp. 1847-1854, Nov. 2016, doi: 10.1021/acs.jchemed.6b00234.

[23] J. J. Evans, A. S. Van Epps, M. T. Smith, S. A. Matei, and E. Garcia, “A transdisciplinary approach for developing effective communication skills in a first-year STEM seminar," in 2015 ASEE Annual Conference and Exposition Proceedings. doi, 2015, vol. 10, p. 23468.

[24] M. Fosmire, A. S. Van Epps, and N. E. Johnson, "Badging your way to information literacy," in Proc. ASEE Annu. Conf. Expo, 2015, pp. 1-11.

[25] J. E. Gaines, "Engineering Design Instruction Using Slack for Project Support and Team- work."

[26] K. T. Ulrich, Product design and development. Tata McGraw-Hill Education, 2003.

[27] E. Wray. "RISE Model for Peer Feedback." Full Sail University, 2011, https://static1.squarespace.com/static/502c5d7e24aca01df4766eb3/t/5c4e71ecf950b77130 d f9756/1548644844456/RISE-Model-Peer-by-Emily-Wray-2018.pdf

[28] National Association of Colleges and Employers NACE. Career Readiness Defined. https://www.naceweb.org/career-readiness/competencies/career-readiness-defined/. 3 Feb. 2020. 